\title{
USO Y DIVULGACIÓN DE LA IMAGEN \\ PERSONAL: ENFOQUES EN EL DERECHO \\ ROMANO, EN EL DERECHO COLOMBIANO \\ Y SU ACTUAL INTERACCIÓN CON LA \\ INTELIGENCIA ARTIFICIAL
}

\author{
MÓNICA LIZET MORALES NEIRA*
}

\section{RESUMEN}

La imagen personal involucra no solo la apariencia física, sino cualquier rasgo que permita individualizar a una persona de manera inequívoca. Su uso y divulgación no es una cuestión reciente, pues se conocen aproximaciones desde el Derecho romano que ligan la imagen personal principalmente al honor que permiten encontrar rasgos coincidentes con las concepciones actuales. En la legislación colombiana vigente se encuentra regulación relativa al derecho a la propia imagen en las normas de derecho de autor, marcario, protección de datos personales, Código de Policía y ahora en el proyecto de reforma del Código Civil; también la Corte Constitucional colombiana lo ha desarrollado como derecho fundamental autónomo. En otros países del mundo, su mayor desarrollo está ligado al régimen de protección de datos personales y de forma similar la imagen es considerada un dato personal biométrico de carácter sensible. Recientemente, con nuevas tecnologías como la Inteligencia Artificial (IA) y sus campos de aplicación, se observa su impacto en el derecho de imagen, surgiendo nuevas preguntas y retos que van a ocupar al Derecho.

\footnotetext{
* Abogada, de la Universidad Externado de Colombia, especialista en Derecho Contractual y Relaciones Jurídico Negociales de la misma Universidad. Máster (Llm) en Derecho Corporativo y en Propiedad Intelectual, Derecho de Información y Tecnología de Ohio State University (eEuu) - Moritz College of Law. Docente de la Universidad Externado de Colombia y abogada líder del Banco de la República. Miembro del Centro Colombiano del Derecho de Autor - Cecolda. Bogotá DC. (Colombia). Correo-e: monica.morales@ uexternado.edu.co. Fecha de recepción: 8 de julio de 2020. Fecha de aceptación: 2 de agosto de 2020. Para citar el artículo: Morales Neira, Mónica Lizet. "Uso y divulgación de la imagen personal: enfoques en el Derecho romano, en el Derecho colombiano y su actual interacción con la Inteligencia Artificial", en Revista de la propiedad inmaterial n. ${ }^{\circ}$ 30, Universidad Externado de Colombia, julio 2020-diciembre 2020, pp. 169-197. DOI. https://doi.org/10.18601/16571959.n30.07
} 
Palabras clave: Imagen; Derecho de imagen; ius imaginis; Derecho de autor; Marcas; Derecho fundamental; Privacidad; Dato personal; Protección de datos; Inteligencia artificial; Aprendizaje automatizado; Visión artificial; Automatización.

\author{
USE AND DISCLOSURE OF PERSONAL IMAGE: APPROACHES \\ IN ROMAN LAW, IN COLOMBIAN LAW AND ITS CURRENT \\ INTERACTION WITH ARTIFICIAL INTELLIGENCE
}

\title{
ABSTRACT
}

Personal Image (PI) involves not only the physical appearance but any element that individualizes unequivocally a person. Image use and dissemination is not a recent issue, in ancient times, Roman Law approached personal image as a matter mainly related to honor, which in some ways relate with current conceptions. Colombian legislation addresses the matter by including regulation regarding image rights in copyright law, trademark law, data protection law, privacy law, the Police Code and now in the draft which would reform the Civil Code. Likewise, Colombian Constitutional Court has developed PI also as an autonomous fundamental right. In other countries, its further development is linked to the personal data protection regime and similarly PI is considered a sensitive biometric personal data. Lately, through technologies such as artificial intelligence (AI) and its fields of application, an impact is seen on image rights, raising new questions and challenges that law will need to address.

Keywords: Image; Image Rights; ius imaginis; Copyright; Trademarks; Fundamental Rights; Right of Privacy; Personal Data; Data Protection; Artificial Intelligence; Machine Learning; Computer Vision; Automation.

\section{INTRODUCCIÓN}

Desde la perspectiva de la antropología social, referirse a la imagen de la persona implica abordar la estrecha relación entre cuerpo e identidad"; en esa medida, "no se

1 "El cuerpo humano es tratado como sujeto de derechos de personalidad por ser un elemento constitutivo de la persona. La persona se hace presente a través de su cuerpo en las relaciones intersubjetivas. Se trata del elemento físico que la identifica (imagen), asemejándola o diferenciándola de aquellos con quien convive (identidad)" Freire de Sá, Fátima. "Cuerpo humano" en Enciclopedia de Bioderecho y Bioética, Romeo Casabona, Carlos M. (Director), https://enciclopedia-bioderecho.com/voces/86. Sobre el cuerpo humano y bioderecho han investigado los juristas colombianos Emilssen González de Cancino y Enrique Santamaría Echeverría, entre otros, en: González de Cancino, E., El cuerpo humano: su importancia en marco del bioderecho en el xxv Congreso Internacional sobre Derecho y Genoma Humano, Bilbao, mayo 2018, https://www.ehu.eus/ es/-/zuzenbideari-eta-giza-genomari-buruzko-xxv-nazioarteko-kongresua; y SANTAMARÍA Echeverría, E. Amputación voluntaria: los casos de la apotemnofilia y el trastorno de integridad corporal, Boletín Derecho y Vida, agosto de 2011, número xcv, Universidad 
puede hablar de identidad sin hacer referencia al cuerpo"'2 pues este es considerado como la "superficie por antonomasia de la identidad"3 y el lugar donde confluyen las expresiones de la individualidad del ser humano.

En un sentido similar la ciencia jurídica ha abordado el derecho a la propia imagen, ya que aquellas legislaciones que reconocen este derecho han fundamentado su protección en su asociación a la identidad personal ${ }^{4}$, así como en conexidad con el buen nombre, la honra y la reputación de las personas naturales.

Tal es el ejemplo del Código Civil italiano que reguló el abuso de la imagen cuando la imagen de una persona o de su familia (progenitores, cónyuge o hijos) haya sido expuesta o publicada, en eventos distintos a los permitidos por la ley, con perjuicio al decoro y reputación de la persona. En tal caso, el interesado podría solicitar a la autoridad judicial competente que disponga que el infractor cese dicho abuso, so pena de resarcir los perjuicios causados.

Asimismo, en un primer momento, Colombia reguló el uso y divulgación de la imagen personal en la ley del derecho de autor ${ }^{6}$, en la cual se estableció el derecho de toda persona a impedir la exhibición o exposición comercial de su retrato si no ha dado su consentimiento expreso para ello, salvo que se trate de ciertos fines específicos permitidos por la ley; así como su facultad de explotarla económicamente, lo cual también está previsto en la legislación marcaria. Con posterioridad, la jurisprudencia de la Corte Constitucional colombiana lo reconoció como una garantía con protección de raigambre constitucional que es expresión directa de la individualidad e identidad de las personas y un derecho fundamental autónomo que puede ser vulnerado junto con los derechos a la intimidad, honra y buen nombre; de esa manera, se tornó en un derecho personalísimo y no únicamente vinculado al retrato.

En Europa y distintos países del mundo, incluido Colombia con la expedición de la Ley General de Protección de Datos, la imagen de una persona se considera un dato personal de carácter biométrico y calificado como sensible con una protección reforzada, lo cual implica que su recolección, uso, divulgación, circulación y supresión estén regidos por normas de protección de datos personales.

En este contexto, si bien esta concepción del derecho a la propia imagen corresponde a desarrollos de finales del siglo XIX y siglo $\mathrm{xx}$, que han continuado su evolución en este siglo, cabe preguntarse si, dada nuestra tradición jurídica romanista, hubo aproximaciones en Roma antigua en torno al uso y divulgación de la

Externado de Colombia, en https://www.uexternado.edu.co/wp-content/uploads/2017/10/ Boletin-DER-Y-VID-95.pdf.

2 Martínez O., Betty. Homo Digitalis: Etnografía De La Cibercultura, Bogotá, Ediciones Uniandes, 2006, p. 3.

3 Ibidem.

4 Rodotá, Stefano. El Derecho a Tener Derechos, Editorial Trotta, Madrid, 2014, Capítulo XI "Cuatro paradigmas para la identidad", pp. 273-283.

5 Codice Civile, Libro Primo "Delle Persona e della familia", Art. 10.

6 Ley 23 de 1982, artículos 36, 87 y 88. 
imagen personal que permitan considerar que este derecho tuvo sus primeros atisbos en el Derecho romano para después analizar su tratamiento en Derecho actual.

De esa manera, en primer lugar, presentaré algunas notas sobre las aproximaciones del uso de la imagen personal en Derecho romano aportando una visión histórica sobre el concepto de imagen y su tratamiento en el ámbito privado. Luego abordaré la regulación del derecho a la propia imagen en Derecho colombiano actual, incluyendo referencias sobre su tratamiento en Europa (Reglamento General de Protección de Datos - RGDP). Finalmente, analizaré la interacción entre imagen personal e inteligencia artificial que recientemente ha tenido impacto, tanto en el uso y explotación de la imagen de las personas, como en replantear la estrecha relación entre imagen personal e identidad de los sujetos, dejando algunas inquietudes abiertas a análisis.

\section{APROXIMACIONES AL USO Y DIVULGACIÓN}

\section{DE LA IMAGEN DE LA PERSONA EN DERECHO ROMANO}

\section{A. Notas SOBRE EL CONCEPTO DE IMAGEN}

Con relación al uso y divulgación de la imagen de la persona en la Roma antigua, es preciso referirse al término latino imago que, si bien tiene distintas acepciones y no es un concepto pacífico, nos centraremos, principalmente, en aquella que la concibe como la mascarilla de cera que reproducía el rostro del difunto en los funerales.

En todo caso, también se ha considerado que los términos imago e imagines podrían ser entendidos de una manera más amplia como la representación de una persona, no solo en dichas mascarillas de cera, sino en bustos, estatuas, monedas, gemas o cualquier otro tipo de retrato ${ }^{7}$. Ejemplo de ello se encuentra en el Senado consulto de Gneo Calurnio Pisón (20 d.c.), acusado de intentar provocar una guerra civil en Siria y de la muerte de Germánico, por el cual se conoce que como penas accesorias que conllevaba los crímenes de perduellio o crimen maiestatis se previeron, entre otras, la destrucción de las estatuas e imagines, tanto públicas y privadas, del reo condenado, así como la prohibición a la familia de incorporar la imago del reo condenado entre las otras imagines de personajes ilustres de su gens y de llevar su imago en las exequiae o pompa funebris ${ }^{8}$. De esa manera, quedaba la prohibición de uso y divulgación de su imagen en el centro de dichas penas, conocidas con el nombre genérico de damnatio memoriae, por ser la memoria del difunto evocación continua de su persona y sus actos en vida.

7 Flower, Harriet. Ancestor Masks and Aristocratic Power in Roman Culture, Oxford University Press, 2000, p. 33.

8 Betancourt, Fernando. El libro anónimo De interdictis: Codex vaticanus latinus, Número 5766. Otra opinión en Badel, Christophe. Une énigme juridique: le jus imaginis romain, en Table ronde: Image et droit (i) Le droit aux images, Université Grenoble Alpes, https://luhcie.univ-grenoble-alpes.fr/wp-content/uploads/2015/04/Badel.pdf 
Resulta interesante también la referencia que encontramos en el pasaje C.9.21.1. que contiene una constitución imperial de Diocleciano y Maximiano de principios del siglo iv d.c. sobre la Ley Viselia, en la que refiriéndose al derecho de los anillos de oro solicitado por un liberto y otorgado por el emperador se pone de presente la dicotomía imaginem-statum; allí se indica que el anillo de oro no le otorga al liberto el estatus de ingenuo sino la "apariencia" de ingenuidad, la cual le permite desempeñar cargos públicos. Conforme a lo anterior, se ha señalado que la concesión del emperador al liberto producía una ficción jurídica, que otorgaba una apariencia de ingenuidad sin que en realidad sea un ingenuo, calidad únicamente reputada de quien nunca había sido un esclavo. Similar contenido tiene un fragmento de Papiniano del libro xI quaestionum, en el que indica que el derecho de los anillos de oro concede la "imagen" de ingenuidad, pero manteniéndose vigentes los derechos de patronato9. Por lo cual, el uso del término de imagen en ambos pasajes hace referencia a una apariencia o semejanza, en este caso, a la ingenuidad.

En este contexto, las principales manifestaciones de uso y divulgación de la imagen de la persona en Roma encontraron como objetivos las de rendir honores y conmemorar aspectos dignos de reconocimiento y remembranza de la vida de la persona, a la vez que constituyó una expresión de su posición social e identidad cultural $^{10}$. En cualquier caso, se podría diferenciar el tratamiento de la imagen de la persona desde distintas perspectivas: por una parte, las referencias a la imagen de la persona en vida y la post mortem, y por otra, los usos en la esfera privada y la esfera pública.

\section{B. USO DE LA IMAGEN DE LA PERSONA EN LA ESFERA PRIVADA}

Este artículo se centrará en el uso de la imagen de la persona en la esfera privada. Sin embargo, no resulta menos interesante la perspectiva de la esfera pública en la que la exhibición de estatuas y otros retratos del príncipe en lugares públicos estaba precedido de la autorización del Senado. En época imperial el príncipe gozaba del privilegio de que aún en vida suya pudieran ser colocadas estatuas que le representasen. De hecho, se considera que fue usual la divulgación de imágenes del emperador en las provincias, especialmente en edificios públicos, lo cual ha sido concebido como un símbolo de la importancia del poder central del emperador en todo el territorio del imperio y como una forma de representar su presencia en centros importantes para la comunidad, como, por ejemplo, los tribunales donde se administraba justicia ${ }^{11}$. La exhibición pública de la imagen también se hizo extensible a ciertas personas, como los constructores o benefactores de obras

9 Guzmán Brito, Alejandro. Derecho Privado Romano, Tomo i. Editorial Jurídica de Chile, Santiago de Chile, 1996, p. 319.

10 Prusac Lindhagen, Marina. From face to face. Recarving Roman portraits and the Late-Antique portrait arts. Brill Academic Publishers, 2011, p. 10.

11 Prusac Lindhagen, Marina, 2011. Op. cit., p. 38. 
públicas, a quienes se les reconocía su generosidad financiera. En todo caso, esta facultad de exhibición de imagen en vida fue restringida por Adriano para mantenerse únicamente como un honor tras el fallecimiento.

Ahora bien, respecto de la imagen personal en la esfera privada, parte de la doctrina hace referencia al denominado ius imaginis que, vale decir, es un término moderno acuñado no antes del siglo $\mathrm{XVI}^{12}$ con fundamento en un pasaje de Cicerón en el Discurso contra Verres ${ }^{13}$ en el que pone de presente el derecho que tenía, en su calidad de edil, a ser retratado para perpetuar su memoria para la posteridad (ius imaginis ad memoriam posteritatemque prodendae).

Con base en fuentes tanto literarias como jurídicas, se ha considerado que el ius imaginis se trataría de una institución de Derecho público que, al parecer, tenía un ámbito restringido respecto de los magistrados curules ${ }^{14} \mathrm{y}$ cuyo contenido se traducía en el derecho de exhibir el retrato de sus antepasados (imagines maiorum) tanto en los funerales como posteriormente en el atrium de la casa ${ }^{15}$.

Mommsen y De Martino hacen referencia al ius imaginis en el marco de las clases privilegiadas de ciudadanos y, en concreto, de la nobilitas ${ }^{16}$. Mommsen indica que la nobleza no tenía privilegios jurídicos como los que correspondían al patriciado y en todo caso reconoce que era un distintivo de la nobleza el derecho a tener en las habitaciones domésticas los retratos de los antepasados que hubieran ejercido algún cargo curul y señala que ello, más que ser un privilegio de clase, es un derecho honorífico concedido a los magistrados curules que tenía gran importancia en el plano político ${ }^{17}$. De Martino, por su parte, manifiesta que no había regulación por el Derecho, sino que consuetudinariamente la nobleza habría tenido privilegios políticos y distinciones formales e indica que de allí el ius imaginis nació de la costumbre de mantener los retratos de antepasados en el atrium de la casa y llevarlos al funeral. De manera previa al surgimiento de la nobleza, se piensa que era un derecho exclusivo del patriciado conocido desde la república patricia.

Se sabe, por relatos de Juvenal, Cicerón, Suetonio, Plinio y Tácito, que en la práctica la mascarilla de cera era hecha a imagen y semejanza de la persona y luego

12 Flower, Harriet. The Encyclopedia of Ancient History, First Edition. Edited by Roger S. Bagnall, Kai Brodersen, Craige B. Champion, Andrew Erksine, and Sabine R. Huebner, pp. 3.554-3.555 (versión impresa), "Ius imaginum".

13 Cicerón, Verr. 5.14.36.

14 Ross Taylor, Lily. "Cicero's Aedileship", The American Journal of Philology, Vol. 60, n.o 2 (1939), p. 198.

15 Ginesta, Josep, Ius Imaginis. Ginesta, Josep, Ius Imaginis en Revista jurídica de Catalunya, ISSN 1575-0078, Vol. 82, n.o 4, 1983, p. 904.

16 Mommsen indica que "La nobleza es un patriciado ampliado, y del patriciado procede, en cuanto este círculo comprendía, además de patricios verdaderos aquellos plebeyos que han salido del patriciado y aquellos otros que a los patricios se equiparan por el cargo público que desempeñan”. De Martino señala que a ella pertenecían los patricios y las estirpes plebeyas, en cuyo seno había habido un magistrado curul, de regla un cónsul. Formaban una verdadera aristocracia y esa cualificación era hereditaria.

17 Mommsen, Teodoro. Compendio del Derecho Público Romano, Analecta editorial, 1999 , p. 75. 
era pintada ${ }^{18}$. Cuando la persona fallecía la mascarilla era usada por un actor que representaba al difunto en el funeral, incluso buscando que tuviera similar estatura y características (simulaba la voz, gestos, modo de andar y expresarse ${ }^{19}$ ). En el cortejo fúnebre le seguían las imágenes de todos los antepasados ya fallecidos que también hubieran adquirido en vida un cargo de magistrado curul ${ }^{20}$, siempre y cuando al momento de su muerte hubieran tenido todos sus derechos civiles y de honor ${ }^{21}$. Después, se volvía a exhibir en los funerales de familiares ${ }^{22}$ con similar calidad y dignidades durante las procesiones fúnebres. Aparte de su uso en funerales, las imágenes se mantenían exhibidas en un armario identificado con una inscripción (titulum) que reseñaba los cargos políticos que había ostentado el difunto, se relataba su linaje, orígenes, genealogía y era mantenido en el atrium de la casa ${ }^{23}$.

Por un fragmento de Valerio Máximo (Val. Máx. VIII 15,1), se tienen noticias de que la gens Cornelia cada vez que enterraba a sus difuntos, solicitaba la presencia de la imagen de Africanus que se encontraba ubicada en el santuario de Júpiter en un lugar cerca a dicho dios. Tácito hace referencia al funeral de Druso acerca del cual se dice que fue especialmente llamativo por la pompa de las imágenes, pues relata que se mostraba a Eneas, origen del linaje de los Julios, todos los reyes de Alba, el fundador de la ciudad, Rómulo; seguidos de la nobleza Sabina, Apio Claudio y todas las demás estatuas de los Claudios ${ }^{24}$. También es Tácito quien relata sobre el funeral de Junia ${ }^{25}$, hija de una hermana de Catón, que llevaba delante veinte estatuas de hombres ilustres, pero señala que las que más resplandecían fueron las que dejaron de llevarse, las de Bruto y Casio, asesinos del César.

Por su parte, una fuente jurídica en la que se evidencia un deber de afección a la imagen de los antepasados, a su recuerdo o memoria alojada en la casa familiar, se encuentra en la constitución imperial C.5.37. 22.3 del emperador Constantino referida a la administración por parte de tutores y curadores del patrimonio de sus pupilos y en la que se establece que no sea lícito vender la casa en la que falleció el padre y creció el menor "en la que es bastante lúgubre no ver fijados los retratos de los mayores o verlos arrancados" y, en todo caso, permanezcan en el patrimonio del menor tanto la casa como los demás inmuebles y no aparezcan arruinados por fraude del tutor, edificio alguno que la herencia daba íntegro.

Como estas, hay diversas fuentes más que dan cuenta de la importancia de la exhibición y uso de las imagines maiorum, por su vínculo con la honra de la persona,

18 Juvenal. 8,2; Plinio. 35,6.

19 Suetonio. Vesp. xix, 6.

20 Cicerón. De orat. 11,225.

21 Ginesta, Josep, Op. cit., p. 908.

22 Plinio 35,2,6.; Tácito, Ann., iv, 9.

23 Flower, Harriet. The Encyclopedia of Ancient History, First Edition. Edited by Roger S. Bagnall, Kai Brodersen, Craige B. Champion, Andrew Erksine, and Sabine R. Huebner, pp. 3.554-3.555 (versión impresa), "Ius imaginum".

24 TÁ́cito, Ann. IV, 9.

25 TÁcito, Ann. ili, 76. 
de su grupo familiar y su rol desde el punto de vista político ${ }^{26}$. Por esto, Cicerón, en su defensa a Sil $a^{27}$ y a Lucio Licinio Murena ${ }^{28}$, manifiesta su preocupación frente a los jueces por los daños a la imagen que podrían derivarse del proceso y, como consecuencia, a la honra de su persona y su memoria frente a sus descendientes. La intención de dejar al menos en herencia una imagen limpia, honrosa y de su memoria incólume e inalterada por la deshonra manifestada materialmente en la exhibición de las imágenes de los antepasados familiares, se estima como un valor profundamente arraigado en la sociedad romana.

El uso de la imagen como soporte ideológico de valores se observa cuando Salustio recuerda que muchas veces ha oído "a insignes varones afirmar que cuando miraban las maiorum imagines sentían en su ánimo un vehemente anhelo de alcanzar la virtus". Asimismo, la evocación a las imágenes de los antepasados eran empleadas por los oradores, por ejemplo en campañas electorales, como evidencias para argumentar su capacidad para ejercer un cargo. De esa manera, los nobiles traen a la memoria los logros de sus antepasados para crear la confianza de que ellos mismos van a llevar a cabo acciones nobles, como si se tratara de una dignidad heredada.

En contraste, Salustio relata el discurso de Mario en la Guerra de Yugurta: "No puedo hacer ostentación, para hacerme creíble, de retratos o triunfos o consulados de mis antepasados, pero sí en cambio, si la ocasión lo demanda, mostrar lanzas, un estandarte, fáleras y otras condecoraciones militares, amén de las cicatrices de las heridas que recibí dando la cara. Estos son mis retratos, esta mi nobleza no recibida en herencia, como la de ellos, sino la que yo me he ganado a base de muchísimos esfuerzos y peligros" (85. 29-30).

En dicho discurso, Mario parece atacar la idea de que la virtus se basa en el nacimiento y en los méritos de sus antepasados. Él, en cambio, en tanto que homo novus, se enorgullece y pone el acento en sus méritos personales, en la virtus militar, como el verdadero medio para obtener renombre. Así como los nobiles traen a la memoria los logros de sus antepasados, el homo novus muestra sus heridas sufridas y demás esfuerzos derivados del cumplimiento de sus deberes políticos y militares; con lo cual, en suma, se destaca la importancia ideológica política que ostentaba tanto la imagen personal propia como la de los antepasados.

\section{Rasgos COMUnes a Destacar}

Si bien en Roma existen aproximaciones o esbozos sobre el uso y divulgación de la imagen de la persona y resultaría un tanto excesivo hablar de un antecedente del derecho a la propia imagen concebido en los términos actuales, en todo caso se

26 Zadoks, Annie y Jitta, Josephus. Ancestral Portraiture in Rome, N.V. NoordHollandsche Uitgevers-miJ., Amsterdam, 1932, pp. 32-46.

27 Cicerón. Pro Sila, 88.

28 Cicerón. Pro Murena, 88. 
advierten algunos rasgos comunes a destacar en la experiencia romana y la actual respecto a la concepción de la imagen de la persona.

Dentro de ellos se destaca la protección de la imagen concretada materialmente en el retrato de la persona que tiene coincidencia con su concepción bajo las normas autorales y civiles que lo conciben como derecho personalísimo. En todo caso, cuando se hace referencia a que en los funerales romanos se representaba al difunto de manera integral, buscando que tuviera similar estatura, características, voz, gestos, modo de andar y expresarse, se observa cómo se esboza una consideración amplia de la imagen más allá de su mera apariencia física sino dándole contenido con otros rasgos. Asimismo, es estrecha la relación de la imagen del individuo con su honra, buen nombre y honor, lo cual actualmente es objeto de protección en el marco del derecho a la propia imagen a nivel constitucional. Además, la consideración de que la custodia y protección de la imagen de una persona podría recaer en su familia hace parte de uno de los elementos vigentes de defensa frente al uso no consentido de la imagen de una persona que ha fallecido. Finalmente, la importancia política y social de la imagen susceptible de generar afectación al honor de la persona se advierte cuando Cicerón habla de "daño" a la imagen como un perjuicio para la persona y su familia y que es aspecto que actualmente la legislación busca proteger a través de los derechos al buen nombre y honra. Entonces, es así como el elemento histórico da luces y esbozos que permiten encontrar rasgos coincidentes con las concepciones actuales.

\section{DERECHO A LA PROPIA IMAGEN EN EL DERECHO COLOMBIANO}

En primer término, como se mencionó, en la actualidad, el concepto de imagen no se limita a la apariencia física de una persona ${ }^{29}$, sino que se reputa de cualquier otro atributo que permita identificarla, como su voz, gestos, pelo, manera de vestir o de hablar, entre $\operatorname{otros}^{30}$. Por su parte, el derecho a la propia imagen tradicionalmente se ha considerado como "un derecho personalísimo relacionado con el derecho a la intimidad y al buen nombre, en virtud del cual toda persona puede exigir que su imagen no sea reproducida por ningún medio sin que medie su consentimien-

29 En todo caso, esta consideración varía en la legislación de algunos países.

30 Resulta interesante el caso White v. Samsung Elec. Am., 971 F.2d 1395, 1397 (9th Cir. 1992) en el que se consideró que Samsung se apropió de la identidad de la presentadora Vanna White del programa "La Rueda de la Fortuna" al usar en un comercial publicitario un robot con el mismo vestido, joyas y estilo de peinado en el contexto del set de programa, reconociéndose la protección al denominado right of publicity, ya que se concluyó que "that "[v]iewed separately, the individual aspects of the advertisement in the present case say little. Viewed together, they leave little doubt about the celebrity the ad is meant to depict". Tratándose de imitadores también se ha considerado que "(...) si una campaña publicitaria no incluye la imagen física de una persona, sino utiliza un imitador que represente la apariencia externa o social de dicha persona, se podría considerar que aun así, se está explotando la imagen de la persona imitada”, Ruiz Rondán, Julián. “¿Se puede usar imágenes de personas en campañas publicitarias?”, en Asuntos Legales, 10 de abril de 2017, en https://www.asuntoslegales.com.co/analisis/julian-david-ruizrondan-532361/se-puede-usar-imagenes-de-personas-en-campanas-publicitarias-2495346 
to y a su vez impedir que terceros le den un uso para ella pernicioso" 31 , en esta definición se conjugan distintas concepciones de leyes, jurisprudencia y doctrina; sin embargo, desde un punto de vista integral de la conceptualización de dicho derecho, su alcance contempla dos dimensiones del mismo, esto es, la facultad de las personas naturales tanto de autorizar como de prohibir el uso y explotación de su propia imagen, lo cual José Miguel Ceballos denomina como "proyección negativo-prohibitiva" y "proyección positivo-dispositiva" del derecho a la propia imagen, que a su vez corresponden a dos facetas del contenido del mismo, la patrimonial y la personal ${ }^{32}$.

En Colombia ${ }^{33}$, el derecho a la propia imagen se encuentra actualmente regulado, por una parte, en la legislación autoral y marcaria y, por otra, en las normas de protección de datos personales. En cuanto a la jurisprudencia, ha sido desarrollado con profundidad por parte de la Corte Constitucional como un derecho fundamental autónomo y a partir de solución de controversias concretas por otros tribunales y la justicia arbitral. Asimismo, cabe mencionar la iniciativa académica de primera versión de Proyecto de Código Civil que contempla en su propuesta referencias al derecho de imagen.

\section{A. Derecho de propia imagen a la luz del DeRecho de AUtor y MARCARio}

En primer término, el derecho de imagen en el marco de las normas de derecho de autor está previsto en la Ley 23 de 1982 en su artículo 87, que establece que toda persona tiene derecho a impedir, con algunas limitaciones, que su retrato se exhiba o exponga en el comercio sin que haya dado expresamente su consentimiento, o el de sus herederos cuando la persona ha fallecido ${ }^{34}$.

Tal consentimiento no es irrevocable, ya que la persona que lo haya dado podrá revocarlo con la indemnización de perjuicios que corresponda al caso concreto, por lo cual es abundante la jurisprudencia que reitera que el otorgamiento de dicho consentimiento no implica la renuncia al derecho y de allí se colige su carácter dispositivo. Conforme el artículo 88 de la misma ley, cuando se quiera poner en el comercio la imagen de un individuo y para ello sea necesario el consentimiento de varias personas entre las cuales haya descuerdo, este lo resolverá la autoridad competente.

31 Ceballos Delgado, José Miguel. "Aspectos Generales del Derecho a la Propia Imagen", en Revista La Propiedad Inmaterial, n.o 15, 2011, p. 68. DoI: https://revistas. uexternado.edu.co/index.php/propin/article/view/2999/2643

32 Ibidem., pp. 68-70.

33 Sobre el derecho de imagen en Colombia véase también Guzmán Delgado, D. F. "El contexto actual del derecho de la imagen en Colombia", en Revista La Propiedad Inmaterial, n. ${ }^{\circ}$ 21, Universidad Externado de Colombia, enero-junio 2016, pp. 47-77. DOI: http://dx.doi.org/10.18601/16571959.n21.03

34 Sobre ¿cómo explicar que quien ya no es persona pueda gozar de derechos de personalidad?: Freire de Sá, Fátima. Op. cit. 
Este derecho encuentra su limitación en el artículo 36 de la misma ley que establece que "La publicación del retrato es libre cuando se relaciona con fines científicos, didácticos o culturales en general o con hechos o acontecimientos de interés público o que se hubieren desarrollado en público", caso en el cual no se requeriría de tal consentimiento para hacer uso del retrato de una persona.

Si bien este derecho está previsto en la Ley de Derechos de Autor, no corresponde, por sí mismo, con un derecho de autor o conexo, "pues como tal no se ejerce sobre una obra, interpretación, fonograma o emisión de radiodifusión" ${ }^{35}$, como lo ha señalado al Dirección Nacional de Derecho de Autor - DNDA. Sin embargo, es un derecho que se interrelaciona con derechos de autor o conexos cuando la imagen de la persona es fijada en una obra o cuando la persona sea, por ejemplo, un artista intérprete o ejecutante y su imagen se fije en una obra audiovisual.

Así las cosas, tratándose de obras que reproduzcan la imagen de una persona, como por ejemplo las obras fotográficas ${ }^{36} \mathrm{o}$ audiovisuales ${ }^{37}$, su utilización estaría supeditada no solo a tener la titularidad de los derechos de autor o conexos, según sea el caso, o licencia para tales fines, sino que también resultaría necesario contar con el consentimiento de la persona cuya imagen está incorporada en la obra ${ }^{38}$, salvo que se esté dentro de las limitaciones previstas en la ley.

Hasta el momento se ha hablado de lo que podríamos denominar perspectiva pasiva del titular del derecho de imagen, quien otorgaría el consentimiento para

35 Ballesteros Valencia, Ricardo. Concepto 1-2005-10700, Bogotá: Dirección Nacional de Derecho de Autor - DNDA, http://derechodeautor.gov.co/, 2005.

36 Mora Cuellar, Manuel A. Concepto 1-2014-11493, Bogotá: Dirección Nacional de Derecho de Autor - DNDA, http://derechodeautor.gov.co/, 2014: "La utilización de obras debe ejercerse sin perjuicio de los derechos a la imagen, intimidad o buen nombre de las personas que sean fijadas en una obra fotográfica, los cuales pueden resultar afectados cuando dichas obras se publiquen sin su consentimiento, motivo por el cual es recomendable contar con su autorización a fin de evitar un posible reclamo por la situación anteriormente descrita”.

37 Guzmán Delgado, D. F. Op. cit, p. 50, refiriéndose a la Ley 1403 de 2010 (Ley Fanny Mikey), indica que "el titular del derecho a la imagen puede ser además titular de derechos conexos. Sin embargo, es necesario que su imagen sea fijada en una obra audiovisual, y que el papel desempeñado esté descrito en el libreto como un personaje principal, secundario o de reparto".

38 Los artículos 89 y 90 de la Ley 23 de 1982 refiriéndose a obras fotográficas y cinematográficas en interacción con el derecho de imagen establecen que "Artículo 89: "El autor de una obra fotográfica, que tenga mérito artístico para ser protegida por la presente ley, tiene derecho a reproducirla, distribuirla, exponerla y ponerla en venta, respetando las limitaciones de los artículos anteriores y sin perjuicio de los derechos de autor cuando se trate de fotografías de otras obras de las artes figurativas. Toda copia o reproducción de la fotografía llevará impresos de modo visible el nombre de su autor, y el año de su realización” y "Artículo 90: "La publicación de las fotografías o películas cinematográficas de operaciones quirúrgicas u otras fijaciones de carácter científico serán autorizadas por el paciente o sus herederos o por el cirujano o jefe del equipo médico correspondiente" (destacado fuera del original). Sánchez Saavedra, Germán A. Concepto 1-2010-6502, Bogotá: Dirección Nacional de Derecho de Autor - DNDA, http://derechodeautor.gov.co/, 2010: "Adicionalmente, debe tenerse en cuenta que en materia de utilización de fotografías donde se plasme la imagen de una persona pueden comprometerse los derechos de esta a la imagen, intimidad o buen nombre, cuando se publiquen las fotografías sin su consentimiento, motivo por el cual resulta recomendable contar con su autorización a fin de garantizar el respeto de los derechos antes descritos". 
su uso por solicitud de un tercero; sin embargo, desde el punto de vista activo del titular el derecho de imagen, si quisiera explotar comercialmente su propia imagen podría optar por distintas tipologías contractuales para disponer de su derecho otorgando licencias de uso de su imagen en contraprestación de una respectiva remuneración, lo cual sería acordado por las partes del respectivo contrato en el marco de la autonomía privada.

En referencia con la explotación comercial de la imagen personal, resulta pertinente referir la posibilidad de registrar marcas que consistan en signos susceptibles de representación gráfica que incorporen elementos que identifiquen a una persona, siempre y cuando se cumpla con determinados requisitos. En la normatividad de la Comunidad Andina, de conformidad con el literal e) del artículo 136 de la Decisión Andina 486 de 2000 de la CAN, no podrán ser objeto de registro las marcas que consistan en un signo que pueda afectar la identidad o prestigio de terceros cuando se trata de elementos de identidad tales como "nombre, apellido, firma, título, hipocorístico, seudónimo, imagen, retrato o caricatura de una persona distinta del solicitante", salvo que se cuente con el consentimiento de esa persona o de sus herederos (en caso de su fallecimiento), el cual deberá ser acreditado ante la autoridad competente, que en Colombia es la Superintendencia de Industria y Comercio.

En aquellos casos en los que la persona quiere registrar como marca algún elemento de su propia imagen, podrá solicitar ante la autoridad su registro sin necesidad de consentimiento ni ningún tipo de requisitos distintos a los inherentes a los propios del análisis sobre si un signo puede constituir marca, esto es la representación gráfica, ser distintivo y no estar incurso en causales de irregistrabilidad.

\section{B. Derecho de propia imagen a la luZ de la jurisprudencia de la Corte Constitucional colombiana}

Desde una perspectiva constitucional, el derecho a la propia imagen ha sido reconocido por la jurisprudencia de la Corte Constitucional colombiana como una garantía de protección de raigambre constitucional y un derecho fundamental autónomo ${ }^{39}$, tornándose en un derecho personalísimo con una especial protección.

Vale decir que son abundantes las sentencias de la Corte Constitucional que se refieren a la imagen personal en sí misma y otras ligadas a otros derechos, como el de la intimidad, dignidad humana, libre desarrollo de la personalidad y buen nombre, ya que muchas de las controversias que se derivan del uso no autorizado de la imagen de una persona han llegado a sede de tutela y no por otras vías judiciales, dada la inmediatez en la protección del derecho que este mecanismo ofrece; es por ello que llegar a la concepción del derecho a la propia imagen como

39 Nogueira Alcalá, Humberto. "El derecho a la propia imagen como derecho fundamental implícito: fundamentación y caracterización”, Ius et Praxis [online]. 2007, vol.13, n.o 2, pp. 245-285, http://dx.doi.org/10.4067/S0718-00122007000200011 
derecho fundamental autónomo ${ }^{40}$ fue fruto de una evolución jurisprudencial que empezó concibiéndolo como un derecho fundamental conexo.

A este respecto, la Corte ha reiterado que "el derecho a la propia imagen es autónomo e inherente a la persona, aun cuando puede ser lesionado de manera concurrente con los derechos a la intimidad, a la honra y al buen nombre (...) constituye una expresión directa de la individualidad e identidad de la persona, y se encuentra estrechamente vinculado a su dignidad y libre desarrollo de la personalidad" 41 .

Asimismo, ha destacado que, si bien la afectación del derecho a la propia imagen se suele concretar en la explotación de la misma sin contar con autorización de su titular, ello no implica que el hecho de que se obtenga autorización para su uso descarte de plano la afectación, por lo cual el juez de tutela deberá analizar el caso concreto en cuestión para determinar si existe o no una vulneración ${ }^{42}$. En este sentido, se ha precisado que, de acuerdo con la interpretación de la Constitución Política, fueron fijados los siguientes parámetros sobre la autorización para el uso o explotación de la imagen: "(i) la autorización para el uso de la propia imagen no puede implicar la renuncia definitiva del mismo; (ii) la autorización comprende el consentimiento informado no solo acerca del uso de la propia imagen sino sobre las finalidades de este; (iii) la autorización de uso de la propia imagen no puede constituir un límite absoluto al carácter necesariamente dinámico y cambiante de la autodeterminación de las personas o a su libre desarrollo de la personalidad, y (iv) la autorización de uso de la propia imagen, como expresión de un acuerdo de voluntades y de la libertad contractual en general, encuentra un límite constitucional en el respeto a los derechos fundamentales" 33 .

Desde ese punto de vista, se coincide con la legislación autoral en la exigencia de contar con consentimiento para la utilización de la imagen, cuyo ejercicio se traduce en una manifestación de la autodeterminación de la persona y exige que las autorizaciones otorgadas para el uso de la propia imagen en el marco de la libertad en las relaciones contractuales no sean entendidas como una renuncia al derecho mismo. En todo caso, la jurisprudencia constitucional plantea un desarrollo ro-

40 Lo cual ocurrió en 2007 en Sentencia T-405 del 24 de mayo de 2007, M.P.: Jaime Córdoba Triviño.

41 Corte Constitucional, Sentencia T-407A-18 del 27 de septiembre de 2018 M.P.: Diana Fajardo Rivera sobre uso y divulgación de la imagen en contenido pornográfico. Para ahondar en la naturaleza y características del derecho a la propia imagen, ver: Corte Constitucional, sentencias T-090 de 1996. M.P.: Eduardo Cifuentes Muñoz; T-471 de 1999. M.P.: José Gregorio Hernández Galindo; T-405 de 2007. M.P.: Jaime Córdoba Triviño; T-634 de 2013. M.P.: María Victoria Calle Correa; T-050 de 2016. M.P.: Gabriel Eduardo Mendoza Martelo. s.P.v. Gloria Stella Ortiz Delgado.

42 Sentencia T-634 de 2013, M.P.: María Victoria Calle Correa. Ver reiteración: Sentencia T-628 de 2017, M.P.: Gloria Stella Ortiz Delgado. Interesante también la sentencia de una acción de tutela contra entidades públicas, Ministerio de Salud y Protección Social e Instituto Nacional de Cancerología, por vulnerar la imagen de una persona, ver Consejo de Estado, Sección Cuarta, 14 de junio de 2018, C.P.: Stella Jeannette Carvajal Basto, Rad n.o 25000-23-37-000-2017-01672-01(AC).

43 Ibidem. 
busto y profundo del derecho a la imagen como derecho fundamental que detalla la naturaleza del derecho, su contenido y alcance y limitaciones de su autorización.

\section{Derecho de propia IMAGen a la LUZ Del RÉGIMen DE PROTECCIÓN DE DATOS PERSONALES}

Desde el año 2012, con la expedición en Colombia de la Ley 1581 de 2012, por la cual se dictan disposiciones generales para la protección de datos personales, se reconoció que la imagen constituye un dato personal y, como tal, se rige por las normas de protección de datos personales ${ }^{44}$. Esta concepción es igualmente compartida por distintas legislaciones latinoamericanas de datos personales y en el Reglamento Europeo de Protección de Datos Personales.

A partir de esta perspectiva, la imagen de una persona se enmarca en el concepto de dato personal que ha sido definido como "cualquier información vinculada o que pueda asociarse a una o varias personas naturales determinadas o determinables" 45 y así lo ha ratificado la Superintendencia de Industria y Comercio ${ }^{46}$, autoridad nacional de protección de datos, al confirmar la calidad de datos personales de las imágenes en los casos en que estas reflejen personas identificadas o identificables. Aunado a lo anterior, si hablando de imágenes faciales se identifica plenamente a la persona serán consideradas como un dato biométrico ${ }^{47} \mathrm{y}$, por ende, entra en la categoría de datos personales sensibles que son aquellos que afectan la intimidad del titular, o cuyo uso indebido puede generar su discriminación y que tienen una especial consideración en su tratamiento y protección reforzada ${ }^{48}$. Si además

44 El régimen de protección de datos en Colombia, cobija, las leyes 1266 de 2008 (Estatutaria de Habeas Data Financiero, Comercial, Crediticio y de Servicios) y 1581 de 2012 (Estatutaria General para la Protección de Datos Personales), así como el Decreto 1074 de 2015 (Decreto Único Reglamentario del Sector Comercio, Industria y Turismo que incorporó los Decretos 1377 de 2013 "Por el cual se reglamenta parcialmente la Ley 1581 de 2012" y 886 de 2014 "Por el cual se reglamenta el artículo 25 de la Ley 1581 de 2012, relativo al Registro Nacional de Bases de Datos"). En todo caso, para efectos de este escrito, no se hará referencia a la Ley 1266 de 2008 y sus normas reglamentarias.

45 Ley 1581 de 2012, Artículo 3, Literal c).

46 Superintendencia de Industria y Comercio, Concepto Jurídico, 24 de junio de 2013. Radicación n. ${ }^{\circ}$ 13-102526-00002-0000.

47 La legislación colombiana no define "dato biométrico" pero como referencia es pertinente indicar que en el Reglamento General de Protección de Datos - RGdp (Reglamento (UE) 2016/679 del Parlamento Europeo y del Consejo de 27 de abril de 2016) en su artículo $4^{\circ}$ numeral 14 se indica lo siguiente: “(..) 14) datos biométricos»: datos personales obtenidos a partir de un tratamiento técnico específico, relativos a las características físicas, fisiológicas o conductuales de una persona física que permitan o confirmen la identificación única de dicha persona, como imágenes faciales o datos dactiloscópicos; “ (destacado fuera del original). Asimismo, en el numeral 51 de las consideraciones de este Reglamento se establece que "El tratamiento de fotografías no debe considerarse sistemáticamente tratamiento de categorías especiales de datos personales, pues únicamente se encuentran comprendidas en la definición de datos biométricos cuando el hecho de ser tratadas con medios técnicos específicos permita la identificación o la autenticación univocas de una persona física" (destacado fuera del original).

48 Ley 1581 de 2012, Artículos 5 y 6 y Decreto 1074 de 2015, Artículo 2.2.2.25.1.3. En el RGDP el tratamiento de categorías especiales de datos personales está previsto en el artículo 9. 
la imagen fuera de niños, niñas o adolescentes, estos también están dentro de una categoría especial de datos personales ${ }^{49}$.

En consecuencia, al ser la imagen un dato personal, su tratamiento, que contempla su recolección, almacenamiento, uso, circulación o supresión ${ }^{50}$, se rige por los principios rectores de la protección de datos ${ }^{51}$, dentro de los cuales se encuentran los de legalidad, finalidad, libertad, veracidad o calidad, transparencia, acceso o circulación restringida, seguridad, confidencialidad, necesidad y responsabilidad demostrada. Igualmente, en el marco de dicho tratamiento habrá personas con la calidad de responsables o encargados ${ }^{52}$ que deberán cumplir, además de los principios antes mencionados con los deberes ${ }^{53}$ que les son aplicables y garantizar los derechos de los titulares del dato personal ${ }^{54}$.

En relación con los principios rectores de la protección de datos personales, como en este caso es la imagen, se destacan especialmente el de legalidad, en virtud del cual se establece que se trata de una actividad reglada que debe sujetarse a lo establecido en las normas que la desarrollen; finalidad, en el que su tratamiento debe buscar un fin legítimo, por lo que al solicitar la autorización se deben explicar al titular las finalidades concretas que se pretenden y en caso de que cambien dicha autorización se deberá solicitar nuevamente; libertad, en virtud del cual se requiere el consentimiento previo, expreso e informado del titular para poder efectuar un tratamiento sobre sus datos, salvo en casos exceptuados por la ley o cuando haya un mandato legal que lo autorice; veracidad o calidad, que vela porque la información sea veraz, completa, exacta y actualizada; transparencia, por el cual el titular podrá acceder a información acerca de la existencia de datos que le conciernan, en cualquier momento y sin restricciones, y necesidad (también denominado de minimización, pertinencia o limitación temporal), por el cual la recolección de los datos únicamente deberá versar sobre los datos que sean pertinentes para la finalidad propuesta y por eso su tiempo de conservación y permanencia en las bases de datos también deberá estar limitada al tiempo necesario para tal finalidad.

Conforme lo anterior, para poder obtener, usar y, en general, realizar cualquier actividad u operación que implique tratamiento de la imagen de una persona será

49 Ley 1581 de 2012, Artículo 7.

50 Ley 1581 de 2012, Artículo 3, Literal g).

51 Ley 1581 de 2012, Artículo 4. El principio de necesidad o minimización se prevé en los Artículos 2.2.2.25.2.1 y 2.2.2.25.2.8 del Decreto 1074 de 2015; asimismo, el de responsabilidad demostrada está en los artículos 2.2.2.25.6.1 y 2.2.2.25.6.2 del mismo Decreto.

52 Ley 1581 de 2012, Artículo 3: "Para los efectos de la presente ley, se entiende por: d) Encargado del Tratamiento: Persona natural o jurídica, pública o privada, que por sí misma o en asocio con otros, realice el Tratamiento de datos personales por cuenta del Responsable del Tratamiento; e) Responsable del Tratamiento: Persona natural o jurídica, pública o privada, que por sí misma o en asocio con otros, decida sobre la base de datos y/o el Tratamiento de los datos; (...)".

53 En especial, los previstos en los artículos 17 y 18 de la Ley 1581 de 2012. "El incumplimiento de cualquiera de las obligaciones previstas en esta ley podrá acarrear sanciones conforme lo allí previsto".

54 Ley 1581 de 2012, Artículo 8. 
necesario contar con previa autorización de la persona titular de la misma, salvo que exista mandato legal o judicial que releve el consentimiento o exceptúe la exigencia de autorización ${ }^{55}$. Tal autorización debe ser obtenida a más tardar en el momento de la recolección de los datos y debe contar con un contenido mínimo previsto en la ley, lo cual difiere de lo que se preveía en la legislación autoral que no necesariamente exigía que el consentimiento fuera previo ni disponía nada en relación con su alcance o contenido.

En tal solicitud de autorización se deben informar al titular, de manera expresa, clara, sencilla y completa, las finalidades específicas que se darán a su imagen persona ${ }^{56} \mathrm{y}$, como se mencionó, si se cambia la finalidad inicialmente informada, será necesario solicitar nuevamente autorización para poder destinar los datos a un nuevo fin. Por tratarse de una autorización informada ${ }^{57}$, debe expresar, como mínimo, el tratamiento al cual serán sometidos los datos personales (la imagen) y su finalidad; el carácter facultativo de las respuestas a preguntas que versen sobre datos sensibles o datos de niños, niñas y adolescentes ${ }^{58}$; en este caso sería informar que es facultativo el suministro de su imagen; los derechos que le asisten al titular y la identificación, dirección física o electrónica y teléfono del responsable del tratamiento; de esta forma, se deberá conservar prueba de la autorización correspondiente, a través de mecanismos que permitan su consulta posterior, ya que uno de los derechos de los titulares es el de solicitarla en cualquier momento.

Frente al modo de obtener la autorización ${ }^{59}$, se prevé que podrá otorgarse de forma oral, por escrito o mediante conductas inequívocas del titular que permitan concluir de forma razonable que otorgó la autorización, ya que en ningún caso el silencio constituye una conducta inequívoca. Resulta evidente la dificultad de obtención y prueba para consulta posterior de una autorización de tratamiento de imagen por conducta concluyente, por lo cual se suele optar por hacerlo de forma oral (grabando en audio o video) o escrita.

Especial mención requiere un caso de tratamiento de imagen facial que está muy difundido y puede resultar problemático dada su masividad que es el de los sistemas de videovigilancia ${ }^{60}$ con que cuentan lugares públicos y privados. $\mathrm{Al}$ respecto, la Superintendencia de Industria y Comerció en 2016 expidió una guía de

55 Ley 1581 de 2012, Artículo 10.

56 Decreto 1074 de 2015, Artículo 2.2.2.25.2.2.

57 Ley 1581 de 2012, Artículo 12.

58 Tratándose de imágenes de menores de edad, dado que la Ley 1581 les da una especial protección por considerarlos una categoría especial de datos, solo podrán ser objeto de tratamiento en la medida en que se responda y respete el interés superior de estos y se asegure el respeto de sus derechos fundamentales. En tal sentido, cumplidos los anteriores requisitos, el representante legal del niño, niña o adolescente será quien debe otorgar la autorización previo ejercicio del menor de su derecho a ser escuchado, conforme el artículo 2.2.2.25.2.9. del Decreto 1074 de 2015.

59 Decreto 1074 de 2015, Artículo 2.2.2.25.2.4.

$60 \mathrm{La}$ Corte Constitucional se ha referido a la videovigilancia en numerosas sentencias, por ejemplo, la T-768 de 2008 sobre el lugar de trabajo; T-407 de 2012, en escuelas públicas; T-487 de 2017 y T-114 de 2018, en establecimientos de comercio, entre otras. 
'Protección de Datos Personales en Sistemas de Videovigilancia' ${ }^{61}$ en la cual señalan que dichos sistemas son intrusivos para la intimidad porque permiten registrar todos los movimientos y actividades de las personas en determinado tiempo, por lo que antes de implementarse debe analizarse su necesidad.

Esta guía contiene, entre otros aspectos, algunas recomendaciones para las personas que vayan a implementar estos sistemas, que consisten en estar al tanto de la normatividad que se expide en esta materia; realizar una evaluación de impacto de privacidad del sistema que se pretende implementar y se analice si efectivamente es necesario para la finalidad perseguida; limitar la recolección de imágenes con criterios de razonabilidad y proporcionalidad con la finalidad y determinar el límite temporal por el cual se van a tratar; obtener la autorización de los titulares, para lo cual se podrán poner avisos o señales distintivos en las zonas de videovigilancia que sean visibles y legibles de forma clara o grabaciones en audio, los cuales deben contar como mínimo con el contenido de un aviso de privacidad (identificación del responsable, tratamiento y finalidad, derechos del titular y dónde está publicada la política de protección de datos); garantizar la implementación de medidas de seguridad y confidencialidad de la información; diseñar políticas de protección de datos personales ${ }^{62}$ que incluyan la atención de reclamos, consultas o peticiones de los titulares, y registrar la base de datos en el Registro Nacional de Bases de Datos $^{63}$ - RNBD, administrado por la sic.

Con relación con la videovigilancia, resulta necesario hacer mención a la Ley 1801 de 2016, Código Nacional de Seguridad y Convivencia Ciudadana (conocido como Nuevo Código de Policía), que en su artículo 237 se refiere a las imágenes recaudadas en este tipo de sistemas y señala que "La información, imágenes, y datos de cualquier índole captados y/o almacenados por los sistemas de video o los medios tecnológicos que estén ubicados en el espacio público, o en lugares abiertos al público, serán considerados como públicos y de libre acceso, salvo que se trate de información amparada por reserva legal", lo que indicaría que el legislador le estaría dando la categoría de dato público a estas imágenes, y por ende no se requeriría obtener autorización para su tratamiento. Asimismo, este artículo establece que se enlacen, de manera permanente o temporal, a la red que disponga la Policía Nacional, los sistemas de vigilancia, de propiedad privada o pública, "que se encuentren instalados en espacio público, áreas comunes, lugares abiertos al público o que siendo privados trasciendan a lo público", según lo que reglamente el Gobierno; se menciona como única excepción los sistemas destinados para la defensa y seguridad nacional y además se señala que para los sistemas "instalados en áreas comunes, lugares abiertos al público o que siendo privados trasciendan a lo público" se requiere "la autorización previa por parte de quien tenga la legi- 
timidad para otorgarla" sin que sea del todo clara la interpretación y alcance de esta frase. Por su parte, esta misma norma, en el artículo $32^{[64]}$, define privacidad de las personas como "el derecho de ellas a satisfacer sus necesidades y desarrollar sus actividades en un ámbito que le sea exclusivo y por lo tanto considerado como privado" y, enseguida, señala los lugares que no se consideran privados.

Estas normas fueron demandadas ante la Corte Constitucional por vulnerar los derechos fundamentales de habeas data e intimidad y por promover el perfilamiento y sujeción de la población a monitoreo y vigilancia estatal indiscriminado. $\mathrm{Al}$ respecto, la Corte, mediante Sentencia C-094/20 del 3 de marzo de 2020, se pronunció, en primer lugar, declarando exequible el artículo 32 por cuanto de la norma no se deduce, como lo afirmaban los demandantes, una regla expresa que indique que el derecho a la privacidad solo se ejerce en los lugares privados; la determinación de los lugares que no son considerados privados, no implica que en ellos el derecho a la intimidad no se ejerza o no deba protegerse; y "se debe concluir que según la jurisprudencia de la Corte el derecho a la intimidad protege un "espacio personal ontológico" o un "espacio del libre desarrollo de la personalidad" y por tanto existe una exigencia mínima de respeto al derecho a la intimidad que se predica en todos los ámbitos y en todos los espacios (públicos, semipúblicos, semiprivados y privados)" ${ }^{\prime 6}$. Respecto del artículo 237, declaró su exequibilidad condicionada "(...) en el entendido de que el manejo y tratamiento de información, datos e imágenes captados y/o almacenados a través de sistemas de video o medios tecnológicos que estén ubicados o instalados en el espacio público, en lugares abiertos al público, en zonas comunes o en lugares privados abiertos al público o que siendo privados trasciendan a lo público, deberá observar los principios de legalidad, finalidad, libertad, transparencia, acceso y circulación restringida, seguridad y confidencialidad y caducidad (...)" y concluyendo que "las imágenes, sonidos o conversaciones de las personas que son captados por cámaras de vigilancia u otros sistemas tecnológicos son, en general, datos personales cuyo tratamiento debe sujetarse a los contenidos del derecho al habeas data", por lo cual, en todo caso, se aplicarán respecto de ellas todos los aspectos mencionados relativos al tratamiento de imágenes como dato personal.

64 Ley 1801 de 2016, Artículo 32: "Definición de privacidad. Para efectos de este Código, se entiende por privacidad de las personas el derecho de ellas a satisfacer sus necesidades $y$ desarrollar sus actividades en un ámbito que le sea exclusivo y por lo tanto considerado como privado. No se consideran lugares privados: 1 . Bienes muebles o inmuebles que se encuentran en el espacio público, en lugar privado abierto al público o utilizados para fines sociales, comerciales e industriales. 2. Los sitios públicos o abiertos al público, incluidas las barras, mostradores, áreas dispuestas para: almacenamiento, preparación, fabricación de bienes comercializados o utilizados en el lugar, así como también las áreas dispuestas para el manejo de los equipos musicales o Disc jockey, y estacionamientos a servicio del público" (destacado fuera del original).

65 Corte Constitucional, Sentencia C-094/20 del 3 de marzo de 2020, M.P.: Alejandro Linares Cantillo. 
USO Y DIVULGACIÓN DE LA IMAGEN PERSONAL: ENFOQUES EN EL DERECHO ROMANO, EN

EL DERECHO COLOMBIANO Y SU ACTUAL INTERACCIÓN CON LA INTELIGENCIA ARTIFICIAL

\section{Derecho de propia imagen a la luz del proyecto de Código Civil}

El 30 de junio de 2020, la Universidad Nacional de Colombia realizó un evento en el que presentó al público el 'Proyecto de Código Civil de Colombia - Primera Versión: Reforma del código civil y su unificación en obligaciones y contratos con el Código de Comercio ${ }^{66}$ y compartió su texto completo con miras a recibir comentarios de parte de la comunidad jurídica que permitan enriquecer el proyecto en su primera versión que estuvo inspirado en el texto elaborado por el jurista Arturo Valencia Zea, en 1983. Contó con la participación de facultades de Derecho de diversas universidades del país, docentes y juristas, y fue coordinado y revisado por José Alejandro Bonivento Fernández, Pedro Lafont Pianetta y Fredy Andrei Herrera Osorio, con el respaldo y apoyo del Ministerio de Justicia y del Derecho.

El citado proyecto de Código Civil contiene 2.069 artículos y está distribuido en siete libros (parte general, bienes, obligaciones, contratos, familia y sucesión por causa de muerte y, el libro final de complementación, observancia y vigencia).

A diferencia del Código Civil vigente, este proyecto de reforma sí regula el derecho de imagen en el artículo 59, ubicado en el libro primero "Parte General", Título III "De las Personas Físicas o Naturales", Capítulo II "Derechos de la personalidad o humanos" ${ }^{67}$, Numeral 4 "Los derechos sobre el nombre, el apellido y la imagen" y que establece que "Toda persona tiene derecho a manejar su imagen, incluido su retrato, efigie y voz, y su utilización requiere previa autorización del titular. No requerirá de autorización el uso que se haga para fines periodísticos, científicos, artísticos o culturales, que no tenga finalidad comercial, lucrativa o publicitaria".

De la revisión de su contenido se observa que se plantea en primer término desde la faceta positiva del derecho de imagen, es decir, como la facultad de toda persona de disponer sobre su propia imagen. Luego, se hace referencia a la imagen en relación con su retrato, efigie y voz, lo cual, aunque si bien amplía la concep-

66 Evento virtual celebrado el 30 de junio de 2020 disponible en Youtube en el canal de la Universidad Nacional de Colombia https://youtu.be/Cp-Ph7sptqQ. El texto completo del proyecto se circuló por medios electrónicos y puede solicitarse en: http:// derecho.bogota.unal.edu.co/proyecto-de-actualizacion-del-codigo-civil/

67 Freire de SÁ, Fátima. Op. cit.: "Son varias las clasificaciones ofrecidas por la doctrina jurídica en relación con los derechos de personalidad. De Cupis (2004) los divide así: derecho a la vida y a la integridad física; derecho sobre las partes del cuerpo y derecho sobre el cadáver; derecho a la libertad; derecho a la intimidad (derecho a la honra, a la intimidad y al secreto); derecho a la identidad personal (derecho al nombre, al título y a la propia imagen); y derecho moral del autor. Antônio Chaves (1982) los relaciona de la siguiente manera: derecho a la honra; derecho al nombre; derecho a la libertad de manifestación de pensamiento; derecho a la libertad de conciencia y de religión; derecho a la protección de la propia imagen; derecho al secreto; derecho moral del autor ( $\mathrm{p}$. 491). La clasificación de Orlando Gomes (2002), muy valorada por la doctrina jurídica, distingue dos bloques fundamentales: derecho a la integridad física, la cual comprende el derecho a la vida, el derecho sobre el propio cuerpo, que se subdivide, a su vez, en derecho sobre el cuerpo como tal y derecho sobre las diferentes partes separadas del mismo; y el derecho sobre el cadáver. El segundo bloque comprende el derecho a la integridad moral: el derecho a la honra, a la libertad, al recato (privacidad), a la imagen, al nombre y derecho moral del autor (p. 153)." 
ción de imagen de la legislación autoral (limitada al retrato o busto) para incluir expresamente la voz, en todo caso, deja un sinsabor al perderse la oportunidad de acoger un concepto más amplio como cualquier rasgo o atributo que identifique inequívocamente a una persona, que, como se mencionó, podría incluso cobijar una especial forma de llevar el pelo, la vestimenta o incluso una forma especial de moverse o expresarse ${ }^{68}$. Señala (al igual que la Ley de Derecho de Autor) que para su uso se exige contar con autorización del titular de la misma, lo cual resulta más acotado que el concepto de tratamiento bajo la consideración de la imagen como dato personal que cobija no solo el uso sino también la recolección, almacenamiento, circulación y supresión. Finalmente, exceptúa del requisito de autorización el uso de la imagen para "fines periodísticos, científicos, artísticos o culturales", de manera similar a la norma de derecho de autor, pero añade que ello es aplicable siempre que "no tenga finalidad comercial, lucrativa o publicitaria".

Más adelante hay menciones a la imagen, pero referidas a "la integridad de la imagen pública del anunciante o el producto" en los contratos de prestación de servicios publicitarios (Artículo 1043) y a la obligación de seguir las reglas sobre "el precio de venta al público, cantidad de productos a colocar, estrategias de mercado y uso de imagen" en los contratos de distribución (Artículo 1251). En el primer evento, siendo los contratos de publicidad aquellos en que más se hace explotación económica de la imagen de personas naturales, a mi juicio, sería una valiosa oportunidad para que el artículo 1043 hiciera mención expresa a que se deberá tener en consideración el cumplimiento de los deberes que se derivan del derecho de imagen personal o que, al menos, se haga remisión al artículo 59.

\section{DERECHO DE IMAGEN E INTELIGENCIA ARTIFICIAL}

Las nuevas tecnologías emergen con supuestos de hecho en torno a la imagen personal que hasta hace unos años no eran cuestión de debate. Por ejemplo, los trasplantes de los tejidos de la cara, la creación de robots antropomórficos y el uso de inteligencia artificial para reconocimiento o generación de imágenes faciales plantean nuevos paradigmas a las concepciones tradicionales.

En lo que respecta a la Inteligencia Artificial ${ }^{69}$ (IA), ha sido considerada como una de las tecnologías disruptivas de este siglo y, aunque se encuentra en una etapa

68 Por ejemplo, sobre cómo la expresión "Todo bien, todo bien” permite identificar al futbolista Carlos El Pibe Valderrama y por la cual es reconocido en todo el país se refiere Guzmán Delgado, D. F., Op. cit., p. 63.

69 Stone, Peter et al. "Artificial Intelligence and Life in 2030." One Hundred Year Study on Artificial Intelligence: Report of the 2015-2016 Study Panel, Stanford University, Stanford, CA, September 2016. Doc: http://ai100.stanford.edu/2016-report, se ha definido la inteligencia artificial como una ciencia y un conjunto de tecnologías computacionales que se inspiran en las formas en que las personas usan su sistema nerviosos para sentir, aprender, razonar y actuar. Por su parte, la Organización para la Cooperación y el Desarrollo Económicos - OCDE en el documento de Principios sobre la Inteligencia Artificial que se suscribió en París en 2019 (https://legalinstruments.oecd. org/en/instruments/OeCD-LEGAL-0449) se la definió como "sistemas basados en máqui- 
temprana de su desarrollo, su auge durante los últimos años se ha debido a algunos factores como Internet, el advenimiento del Big Data, el aumento de la capacidad de almacenamiento y la sofisticación de los algoritmos.

En la actualidad, algunas de las subdisciplinas o áreas de investigación y aplicación de la ia que tienen relación estrecha con el derecho de imagen por usar o divulgar la imagen de individuos (en especial la facial) son, entre otras, las de visión artificial (computer vision), aprendizaje automatizado (machine learning) o aprendizaje profundo (deep learning), las cuales convergen entre sí.

A través de visión artificial (computer vision), la máquina captura, procesa, analiza e interpreta una imagen y de ella extrae determinada información que clasifica; así, a partir de una fotografía, video o audio y habiendo sido entrena$\mathrm{da}^{70}$ con información determinada, la máquina podría identificar a las personas allí presentes con sus nombres y otros datos personales, tal como funcionan los algoritmos de reconocimiento facial de redes sociales como Facebook. Esta subdisciplina ha sido de las que más crecimiento ha tenido en el campo de la IA, por lo que hoy se considera que la visión artificial ya ha superado en ciertos aspectos la capacidad humana.

En el área de aprendizaje automatizado (machine learning) se establecen métodos para que la máquina aprenda automáticamente a partir de la experiencia y el entrenamiento (basados en información) y esto permite encontrar resultados (predicciones, patrones, conclusiones, recomendaciones y, en general, otra información) para los cuales no fue inicialmente programada. Por su parte, en el aprendizaje profundo (deep learning), subcampo del anterior, ello ocurre mediante el uso de diversas capas de redes neuronales artificiales; en concreto, a la luz de estos métodos de ia, habría la posibilidad de entrenar la máquina con datos de entrada que podrían consistir en fotografías, videos u otros soportes que fijen la imagen de una persona para que aprenda de ellos, los analice y arroje nueva información o ejecute alguna tarea. Asimismo, como dato de salida tras el entrenamiento (resultados) la máquina podría generar imágenes de personas, reales o ficticias.

Como ejemplos en cuanto a imagen facial de personas se refiere, estas subdisciplinas han tenido distintas aplicaciones en sistemas biométricos de seguridad y videovigilancia, migratorios y fronterizos, de identificación del cliente en el sistema financiero $u$ otros sectores, de reconocimiento facial en redes sociales ${ }^{71} \mathrm{o}$ en

nas, que teniendo un conjunto de objetivos fijados por el ser humano, son capaces de hacer predicciones, recomendaciones o tomar decisiones que influyan en entornos reales o virtuales. Pueden tener distintos niveles de autonomía”. En Colombia, el Documento Conpes 3975 "Política Nacional para la Transformación Digital e Inteligencia Artificial” la define como "un campo de la informática dedicado a resolver problemas cognitivos comúnmente asociados con la inteligencia humana o seres inteligentes, entendidos como aquellos que pueden adaptarse a situaciones cambiantes. Su base es el desarrollo de sistemas informáticos, la disponibilidad de datos y los algoritmos".

70 Estas subdisciplinas se relacionan entre sí, en este caso la relación computer vision machineldeep learning en que la máquina podría ser entrenada a través de distintos tipos de aprendizaje: supervisado, no supervisado, reforzado, auto supervisado, estadístico, etc.

71 Morales Neira, Mónica L. "Notas sobre el caso de Facebook y Cambridge 
aplicaciones de entretenimiento que identifican emociones a partir de expresiones faciales, en los controvertidos sistemas de reconocimiento facial que empezaron a usar recientemente en los Estados Unidos para law enforcement ${ }^{72}$, que hacen perfilamiento de las personas, además de estar presente en carros autónomos para la identificación de peatones, entre otros.

Otros son los usos cuando la imagen personal es el dato de salida, es decir, el resultado del entrenamiento de la máquina (se conoce como IA "creativa") que, como ejemplos más conocidos, son los que se usan en entretenimiento, por ejemplo, aplicaciones para transformar la cara y mostrar a las personas cómo lucirían si tuvieran mayor o menor edad, si fueran de otro sexo, si tuvieran otros rasgos faciales, etc., como el caso de la aplicación Faceapp a la que tanto se le ha cuestionado su tratamiento de datos personales y privacidad; también aquellas que intercambian caras de una persona a otra y que en ocasiones lo hacen en video de forma tan realista que se han vuelto virales en Internet (algunos de Donald Trump, Ángela Merkel y Vladimir Putin) con audios que no corresponden con el discurso que han dado sino cantando canciones; otros de famosos del cine, la televisión o el deporte protagonizando videos pornográficos falsos y ya están empezando las jugadas políticas electorales con estas herramientas; otras se usan para crear personas ficticias con rasgos perfectamente reales que a simple vista sería imposible distinguir, como los creados por una red neuronal denominada GAN (Generative Adversarial Network) $\mathrm{y}$ disponibles en el sitio web Thispersondoesnotexist.com $/{ }^{73} \mathrm{y}$ que, en ocasiones, no tienen un fin concreto más que demostrar la tecnología hiperrealista, pero en otros se usan en videojuegos e incluso también en la pornografía.

Un afortunado ejemplo de imágenes generadas por IA se ve en The Dalí Museum, de Florida, que ha logrado dar vida nuevamente a Salvador Dalí y cuenta

Analytica: modelos de negocio que se basan en la explotación de datos personales", en Boletín Propiedad Intelectual, Universidad Externado de Colombia, 13 de abril de 2018, disponible en: https://propintel.uexternado.edu.co/notas-sobre-el-caso-de-facebook-ycambridge-analytica-modelos-de-negocio-que-se-basan-en-la-explotacion-de-datos-personales/: "Facebook tiene en su poder la base de datos privada más grande del mundo de reconocimiento facial (más de 2 billones de usuarios y aquellos que no son usuarios pero aparecen en las fotos subidas en la red social). Asimismo, Facebook (al igual que muchas otras compañías del sector) utiliza gran capital en lobby (en 2017 casi 9 millones de euros) para evitar o incidir en las regulaciones que le implicarían mayores controles u obstáculos en su modelo de negocio, hace contribuciones directas a la campaña de muchos legisladores (y aparentemente el mayor contribuyente a los comités que lo cuestionaron en el Congreso), y, por ejemplo, en Illinois hace parte de Consejo Tecnológico de la Cámara de Comercio de Illinois que ha apoyado la modificación de la ley BIPA".

72 En ese país mucho se ha discutido sobre el tema y diversas leyes estatales se han planteado prohibir esta práctica por su relación más que problemática con la privacidad. En otros países también se ha iniciado la discusión de sistemas de reconocimiento facial para uso de la policía para evitar el crimen en las calles; de hecho, así lo proponían algunos de los candidatos en las elecciones a alcaldías de las principales ciudades de Colombia.

73 Sobre este tema véase De Vries, Katja (2020). You never fake alone. Creative AI in action", en Information, Communication \& Society, DOI: 10.1080/1369118X.2020.1754877; y Calo, Ryan, People Can Be So Fake: A New Dimension to Privacy and Technology Scholarship (August 27, 2009). Penn State Law Review, Vol. 114, No. 3, 2010. Available at sSRN: https://ssrn.com/abstract $=1458637$ 
con alrededor de 125 videos interactivos en los que de forma hiperrealista aparece el artista y brinda información sobre su obra e interactúa con los visitantes ${ }^{74}$; también Disney anunció recientemente que han desarrollado un algoritmo de intercambio automático de caras en video y fotografía que, dada su sofisticación e hiperrealismo, va a ser en el corto plazo una herramienta de efectos visuales para sus películas ${ }^{75}$, lo que hará que se difunda su uso en la producción de cine y televisión.

En este contexto, surgen diversos problemas jurídicos alrededor de la interacción entre sistemas basados en inteligencia artificial y uso de la imagen personal. En primer lugar, los relativos al uso de imagen y los requisitos que desarrolladores de IA deberían cumplir para entrenar a las máquinas con abundantes cantidades de imágenes de personas, esto es, la obtención del consentimiento de parte de los titulares de la forma más estricta, como lo solicitan las normas de protección de datos personales y cumpliendo los demás deberes que el ser responsable de una base de datos de este tipo entraña, aunque también es cierto que algunas de las bases de datos que se han venido usando estarían anonimizadas (o seudonimizadas) por consistir en rasgos faciales independientes sin asociarse al rostro completo de una persona.

Cuando sí constituyen dato personal surgen varios temas de discusión sobre: la necesidad de la obtención de la autorización, pues algunos se podrían preguntar ¿son estos fines científicos o culturales que exceptúen la obtención de tal consentimiento como indica la legislación autoral, el proyecto de Código Civil y el artículo 10 de la Ley 1581? Las implicaciones que la elaboración de perfiles de forma automatizada con IA tienen sobre la vida de las personas y que podrían ser fuente de discriminación, razón de decisiones sobre celebrar o no negocios jurídicos (otorgar o no un seguro o un crédito, prestar un servicio, etc.), análisis de preferencias para mercadeo y prestación de servicios, etc.; el siempre latente riesgo a una intromisión a la intimidad de los individuos por el Estado ${ }^{76} \mathrm{y}$ empresas privadas que, en ciertos casos, preocupa tengan más poder que los mismos gobiernos y que su modelo de negocio se basa en la explotación de la imagen personal, lo que hace preguntarse ¿dónde quedan las garantías constitucionales sobre el derecho a la propia imagen?, ¿el individuo y en su ausencia sus familias han perdido el control de la protección de su imagen ${ }^{77}$ ?, y ¿a falta de ellos lo han perdido las autoridades?, ¿̇iendo la imagen

74 Dalí Lives (via Artificial Intelligence) https://thedali.org/exhibit/dali-lives/; el detrás de escenas de cómo funciona el algoritmo para crear la imagen de video de Dalí se encuentra en el sitio de Youtube del museo en https://www.youtube.com/watch?v=BIDaxl4xqJ4

75 J. Naruniec et al. High-Resolution Neural Face Swapping for Visual Effects. Eurographics Symposium on Rendering 2020, Volume 39, 2020, Number 4, http://studios. disneyresearch.com/2020/06/29/high-resolution-neural-face-swapping-for-visual-effects/; en el sitio de Youtube de Disney Research Hub se encuentra el video explicativo de cómo funciona: https://youtu.be/yji0t6KS7Qo

76 Crawford, Kate; Roel, Dobbe; Theodora Dryer, et al. AI Now 2019 Report. New York, AI Now Institute, 2019, https://ainowinstitute.org/AI_Now_2019_Report.html.

77 Freire de SÁ, FÁtima, Op. cit.: “Asumir la existencia del cuerpo como algo personal implica, necesariamente, el reconocimiento y la legitimación de la autonomía privada como forma de autodeterminación de la persona humana, y evidentemente de su iden- 
esencial para nuestra identidad y con tanto impacto en nuestra propia vida dejarla en manos de grandes empresas? Y ¿se ha reducido la imagen a "un dato más" que se autoriza sin un análisis concienzudo?

En la legislación colombiana no se aborda expresamente el tema del tratamiento automatizado de datos personales ni el perfilamiento, como sí en el Reglamento General de Datos Personales europeo que indica que elaboración de perfiles es "toda forma de tratamiento automatizado de datos personales consistente en utilizar datos personales para evaluar determinados aspectos personales de una persona física, en particular para analizar o predecir aspectos relativos al rendimiento profesional, situación económica, salud, preferencias personales, intereses, fiabilidad, comportamiento, ubicación o movimientos de dicha persona física"78 y en sus artículos 21 y 22 se refiere al derecho de oposición que tienen los individuos de ser perfilados, incluyendo algunos matices, así como el derecho a no ser objeto de una decisión basada únicamente en el tratamiento automatizado, incluida la elaboración de perfiles, que produzca efectos jurídicos en él o le afecte significativamente de modo similar. En todo caso, los países que tienen regímenes de protección de datos personales como Colombia, pese a no tratar la automatización expresamente, tienen en sus normas y jurisprudencia todos los elementos para hacer proteger el uso y divulgación de la imagen personal de forma completa y robusta frente al tratamiento que sobre esta pueda realizarse en el marco de desarrollo de IA y, según el caso concreto, habría que analizar qué deberes y exigencias tendrían los responsables de tales bases de datos, según la finalidad para la que la estén destinando ${ }^{79}$, como se señaló en la sección anterior.

Por otra parte, frente la generación de videos o fotografías de personas ficticias o de personas reales pero manipuladas en otros contextos, surgen preocupaciones sobre los denominados deepfake y el desmoronamiento de la confianza del público frente este tipo de documentos, así como las posibles afectaciones al buen nombre de personas o a marcas asociadas a personajes públicos. En un mundo de noticias falsas (fake news) que tanto daño hacen, ahora enfrentarnos a videos o fotos hiperrealistas que no nos permitan a simple vista identificar si son falsos, pone en juego la credibilidad de estos documentos como medio de prueba que generaría incertidumbre en la ciudadanía y requeriría de peritos expertos para resolver estas dudas. Lo anterior preocupa además a las oficinas de inteligencia de gobiernos por difuminar la línea entre la realidad y la ficción ${ }^{80}$ e incrementar la circulación de

tidad, en una red de interlocución. El cuerpo humano es, por lo tanto, la expresión de la propia persona en este proceso de autodeterminación, tanto para atribuir contenido a su integridad física como para delimitar las coordenadas de su orientación psíquica”. 78 RGDP, Artículo 4 "Definiciones".

79 El asunto de la finalidad es debatido, pues a través de IA muchas veces se obtienen conclusiones y usos impredecibles o para los que la máquina inicialmente no estaba programada, por lo que informar la titular ex ante de todas las finalidades para las cuales se podría usar su imagen, resultaría problemático.

80 National Academies of Sciences, Engineering, and Medicine. 2019. Robust Machine Learning Algorithms and Systems for Detection and Mitigation of Adversarial Attacks and 
información falsa, que en ocasiones es tan basta que resulta difícil de controlar y para la opinión pública podría parecer información veraz.

De esa manera, para analizar la interacción entre IA y derecho de imagen que se ha esbozado previamente, es importante agudizar el sentido de la ponderación que favorezca la innovación al tiempo que se protegen y respetan los derechos fundamentales y valores democráticos que es lo que los distintos principios que se han planteado para la IA (como los de la $\operatorname{OCDE}^{81}$ ) han buscado señalar como que es una tecnología centrada en el ser humano y no al revés, que debe estar dotada de justicia, transparencia, responsabilidad, confidencialidad, robustez y seguridad.

\section{CONCLUSIONES}

La imagen personal hoy en día involucra no solo la apariencia física, sino cualquier rasgo que permita individualizar a una persona de manera inequívoca, extendiéndose incluso a sus maneras, gestos, forma de vestir, entre otras. En la legislación colombiana vigente se encuentra regulación relativa al derecho a la propia imagen en las normas de derecho de autor, marcario, protección de datos personales, Código de Policía y ahora en el proyecto de reforma del Código Civil; en otros países también está contemplado en este mismo tipo de normas y su mayor desarrollo reciente está bajo la sombrilla de la protección de datos personales. La jurisprudencia constitucional colombiana ha sido vasta en estudiar este derecho como fundamental autónomo y cuenta con criterios estables y robustos para la interpretación.

En todo caso, el uso y divulgación de la imagen no es una cuestión reciente, sino que conocemos aproximaciones desde el Derecho romano que ligan la imagen personal principalmente al honor que permiten encontrar rasgos coincidentes con las concepciones actuales. Tampoco es un tema estático pues, como se analizó, nuevas tecnologías como la Inteligencia Artificial (IA) nos plantean nuevas preguntas y retos que van a ocupar al Derecho.

Conforme el Derecho vigente, la imagen es un concepto amplio con facetas patrimoniales y personalísimas, con una doble perspectiva consistente, por una parte, en la facultad de disponer activamente de la propia imagen y en ocasiones obtener remuneración por este hecho y, por otra, de oponerse o prohibir el uso que hagan terceros sin su consentimiento, salvo que se esté en algunas de las excepciones de ley. También que la imagen de un individuo constituye un dato personal sensible que tiene una protección reforzada y exige que aquel que decida hacer tratamiento de ella (lo que a diferencia de las normas de derecho de autor no solo es uso y divulgación para fines comerciales, sino también obtención,

Anomalies: Proceedings of a Workshop. Washington, DC, The National Academies Press. https://doi.org/10.17226/25534.

81 Organización para la Cooperación y el Desarrollo Económicos - OCDE, Principios sobre la Inteligencia Artificial suscritos en París en 2019, disponible en https://legalinstruments.oecd.org/en/instruments/OECD-LEGAL-0449 
almacenamiento, circulación y supresión para otros fines) debe cumplir con los principios rectores y deberes inherentes a la protección de datos personales, so pena de incurrir en sanciones.

En épocas recientes, se evidencian los innumerables beneficios que brinda una tecnología como la IA para mejorar la capacidad de ciertas tareas y procesos antes ejecutados exclusivamente por humanos; ello conlleva mejoramiento de productividad, innovación, crecimiento económico y científico, avances en distintas áreas de investigación, acceso al conocimiento e información de valor, entre otros; pero, a la par, surgen preocupaciones en torno a la utilización de la imagen personal por parte de la IA que, como cualquier herramienta, también habilita para usos no coincidentes con los valores democráticos de la sociedad y podría terminar automatizando la desigualdad, la desinformación, los prejuicios y la discriminación que tanto el Derecho ha buscado erradicar.

Recordemos que "resulta también indiscutible la idea del cuerpo como un referente cultural y como elemento de interacción social" ${ }^{22}$ y que los individuos en nuestras acciones moldeamos el contenido de la imagen que queremos proyectar a terceros ${ }^{83}$; por eso, ser perfilados y que con ello se tomen decisiones sobre nuestra vida o ser objeto de manipulación nos pone en un contexto falso (pronunciando palabras que nunca dijimos, o en situaciones criminales o que afecten el buen nombre, etc.) son riesgos que pueden materializarse dado el avance de la IA.

Frente a este panorama, es útil voltear nuestra mirada al Derecho romano que muestra como el Derecho, privilegio o costumbre (según la posición que se adopte) de uso y divulgación de la imagen estaba ligada al honor, a los méritos personales y familiares basados en el servicio a la res publicae y así a su consideración actual como derecho fundamental ligado a la intimidad y buen nombre y como derecho personalísimo que puede ser defendido por la persona o sus familiares teniendo estos el control de su divulgación, en vez de dejarlo al vaivén de intereses económicos o políticos de terceros ${ }^{84}$.

El Derecho no puede abstraerse de su sentido crítico y valorativo de los nuevos supuestos de hecho y problemas jurídicos que la tecnología nos trae, ni tampoco ser un mecanismo de ahogo de la innovación, pues, a la larga, quedaría relegado. Esta es una discusión interdisciplinaria, que busque fijar mínimos fundamentales sin ahogar la autonomía y que, en todo caso, tenga como fin la protección del individuo y sus derechos.

82 Santamaría Echeverría, E., Op. cit., p. 1.

83 Nogueira Alcalá, Humberto. Op. cit.

84 Rodotá, Stefano. Op. cit., p. 283: “La persona no puede ser simplificada arbitrariamente para instalarla con más facilidad en categorías que corresponden a los intereses de una multiplicidad de sujetos externos, juristas incluidos. Debe ser seguida en su multiforme itinerario, sin pretensiones autoritarias, sino construyendo pacientemente el contexto en el que sus derechos fundamentales puedan obtener no solo reconocimiento, sino cumplimiento". 
USO Y DIVULGaCión DE LA IMAGEN PERSONAL: ENFOQUES EN EL DERECHO ROMANO, EN EL DERECHO COLOMBIANO Y SU ACTUAL INTERACCIÓN CON LA INTELIGENCIA ARTIFICIAL

\section{REFERENCIAS}

\section{Derecho romano}

Badel, Christophe, Une énigme juridique: le jus imaginis romain, en Table ronde: Image et droit (i) Le droit aux images, Université Grenoble Alpes, https://luhcie. univ-grenoble-alpes.fr/wp-content/uploads/2015/04/Badel.pdf

Betancourt, Fernando, El libro anónimo De interdictis: Codex vaticanus latinus, Número 5766.

Flower, Harriet, Ancestor Masks and Aristocratic Power in Roman Culture, Oxford University Press, 2000.

Flower, Harriet, The Encyclopedia of Ancient History, First Edition. Edited by Roger S. Bagnall, Kai Brodersen, Craige B. Champion, Andrew Erksine, and Sabine R. Huebner, pp. 3.554-3.555 (versión impresa), "Ius imaginum".

Ginesta, Josep, "Ius Imaginis”, en Revista jurídica de Catalunya, ISSN 1575-0078, Vol. 82, n. ${ }^{\circ} 4$, 1983, pp. 897-916.

Guzmán Brito, Alejandro, Derecho Privado Romano, Tomo I. Editorial Jurídica de Chile, Santiago de Chile, 1996.

Miquel, Joan, Derecho Privado Romano, Marcial Pons, Ediciones Jurídicas, Madrid, 1992.

Mommsen, Teodoro, Compendio del Derecho Público Romano, Analecta editorial, 1999.

Prusac Lindhagen, Marina, From face to face. Recarving Roman portraits and the Late-Antique portrait arts. Brill Academic Publishers, 2011, p. 10.

Ross TAylor, Lily, "Cicero's Aedileship", en The American Journal of Philology, Vol.60, n.o 2, 1939, pp.194-202.

Zadoks, Annie y Jitta, Josephus. Ancestral Portraiture in Rome, N.V. NoordHollandsche Uitgevers-MIJ., Amsterdam, 1932, pp. 32-46.

\section{Derecho aCtual}

Ballesteros Valencia, Ricardo, Concepto 1-2005-10700, Bogotá: Dirección Nacional de Derecho de Autor - DNDA, http://derechodeautor.gov.co/, 2005. Calo, Ryan, "People Can Be So Fake: A New Dimension to Privacy and Technology Scholarship (August 27, 2009)", en Penn State Law Review, Vol. 114, n. ${ }^{\circ}$ 3, 2010. Available at SsRn: https://ssrn.com/abstract=1458637

Ceballos Delgado, José Miguel. "Aspectos Generales del Derecho a la Propia Imagen”, en Revista La Propiedad Inmaterial, n. o 15, 2011, p. 68. Dor: https:// revistas.uexternado.edu.co/index.php/propin/article/view/2999/2643

Codice Civile Italiano. 
Crawford, Kate, Roel Dobbe, Theodora Dryer et al., AI Now 2019 Report. NewYork: AI Now Institute, 2019, https://ainowinstitute.org/AI_Now_2019_ Report.html.

Dalí Lives (via Artificial Intelligence) https://thedali.org/exhibit/dali-lives/;

Decisión Andina 486 de 2000 de la Comunidad Andina de Naciones - CAN.

Decreto 1074 de 2015.

De Vries, Katja, You never fake alone. Creative AI in action", en Information, Communication \& Society, 2020, doi: 10.1080/1369118X.2020.1754877

Documento Conpes 3975 "Política Nacional para la Transformación Digital e Inteligencia Artificial".

Freire de SÁ, Fátima, "Cuerpo humano", en Enciclopedia de Bioderecho y Bioética, Romeo Casabona, Carlos M. (director), https://enciclopedia-bioderecho.com/ voces/86.

GonZÁlez de CANCINo, E., El cuerpo humano: su importancia en marco del bioderecho en el xxv Congreso Internacional sobre Derecho y Genoma Humano, Bilbao, mayo de 2018, https://www.ehu.eus/es/-/zuzenbideari-eta-giza-genomari-buruzko-xxv-nazioarteko-kongresua

Guzmán Delgado, D. F., "El contexto actual del derecho de la imagen en Colombia", en Revista La Propiedad Inmaterial, n. ${ }^{\circ} 21$, Universidad Externado de Colombia, enero-junio 2016, pp. 47-77. Dor: http://dx.doi. org/10.18601/16571959.n21.03

J. Naruniec et al., High-Resolution Neural Face Swapping for Visual Effects. Eurographics Symposium on Rendering 2020, Volume 39 (2020), Number 4, http://studios.disneyresearch.com/2020/06/29/high-resolution-neural-faceswapping-for-visual-effects/;

Leyes 23 de 1982, 1581 de 2012 y 1801 de 2016.

Martínez O., Betty, Homo Digitalis: etnografía de la Cibercultura, Bogotá, Ediciones Uniandes, 2006, p. 3.

Mora Cuéllar, Manuel A., Concepto 1-2014-11493, Bogotá: Dirección Nacional de Derecho de Autor - DNDA, http://derechodeautor.gov.co/, 2014.

Morales Neira, Mónica L., "Notas sobre el caso de Facebook y Cambridge Analytica: modelos de negocio que se basan en la explotación de datos personales", en Boletín Propiedad Intelectual, Universidad Externado de Colombia, 13 de abril de 2018, en: https://propintel.uexternado.edu.co/notas-sobre-elcaso-de-facebook-y-cambridge-analytica-modelos-de-negocio-que-se-basanen-la-explotacion-de-datos-personales/

National Academies of Sciences, Engineering, and Medicine. Robust Machine Learning Algorithms and Systems for Detection and Mitigation of Adversarial Attacks and Anomalies: Proceedings of a Workshop. Washington, DC: The National Academies Press, 2019. https://doi.org/10.17226/25534.

Nogueira Alcalá, Humberto, "El Derecho a la propia imagen como Derecho Fundamental Implícito: fundamentación y caracterización", en Ius et Praxis 
[online]. 2007, vol.13, n.2, pp.245-285, http://dx.doi.org/10.4067/S071800122007000200011

Organización para la Cooperación y el Desarrollo Económicos - OCDE, Principios sobre la Inteligencia Artificial suscritos en París en 2019 (https://legalinstruments. oecd.org/en/instruments/OECD-LEGAL-0449)

Proyecto de Código Civil de Colombia - Primera Versión: Reforma del código civil y su unificación en obligaciones y contratos con el Código de Comercio.

Reglamento General de Protección de Datos - RGDP (Reglamento (UE) 2016/679 del Parlamento Europeo y del Consejo de 27 de abril de 2016).

Rodotá, Stefano, El Derecho a Tener Derechos, Editorial Trotta, Madrid, 2014.

Ruiz RondÁn, Julián, “¿Se puede usar imágenes de personas en campañas publicitarias?”, en Asuntos Legales, 10 de abril de 2017, en https://www.asuntoslegales.com.co/analisis/julian-david-ruiz-rondan-532361/se-puede-usarimagenes-de-personas-en-campanas-publicitarias-2495346

Sánchez Saavedra, Germán A., Concepto 1-2010-6502, Bogotá: Dirección Nacional de Derecho de Autor - DNDA, http://derechodeautor.gov.co/, 2010. Santamaría Echeverría, E., "Amputación voluntaria: los casos de la apotemnofilia y el trastorno de integridad corporal", en Boletín Derecho y Vida, agosto de 2011, número xcv, Universidad Externado de Colombia, en https://www. uexternado.edu.co/wp-content/uploads/2017/10/Boletin-DER-Y-VID-95.pdf.

Sentencia Consejo de Estado, Sección Cuarta, 14 de junio de 2018, C.P.: Stella Jeannette Carvajal Basto, Rad n. ${ }^{\circ}$ 25000-23-37-000-2017-01672-01(AC).

Corte Constitucional, Sentencias T-090 de 1996, T-471 de 1999, T-405 de 2007 , T-768 de 2008, T-407 de 2012, T-634 de 2013, T-050 de 2016, T-487 de 2017, T-628 de 2017, T-114 de 2018, T-407A de 2018 y C-094 de 2020.

Stone, Peter et al., "Artificial Intelligence and Life in 2030." One Hundred Year Study on Artificial Intelligence: Report of the 2015-2016 Study Panel, Stanford University, Stanford, CA, September 2016. Doc: http://ai100.stanford. edu/2016-report

Superintendencia de Industria y Comercio, Concepto Jurídico, 24 de junio de 2013. Radicación n. ${ }^{\circ}$ 13-102526-00002-0000.

Superintendencia de Industria y Comercio, Protección de Datos Personales en Sistemas de Videovigilancia, 2016, https://issuu.com/quioscosic/docs/guia_vigilancia_2016

White v. Samsung Elec. Am., 971 F.2d 1395, 1397 (9th Cir. 1992). 